\title{
Endotoquia matricida em Rhabditis sp. (Nematoda, Rhabditidae)
}

\author{
LUIZ GONZAGA E. LORDELLO
}

(Assistente da Cadeira de Zoologia da Escola Superior de Agricultura "Luiz de Queiroz" da Universidade de S. Paulo)

Em março de 1951, ao examinar material de cenoura (solo e raízes), visando o encontré de Nematóides, tivemos ocasião de constatar a presença de uma espécie interessante do gèncro Rhabditis, em que eram relativamente frequentes os casos de "endotoquia matricida" ou "eclosão intrá-uterina matricida dos ovos".

O material foi coligido pelo Dr. Leocádio de Souza Camargo na Estação Experimental de Monte Alegre do Sul, do Instituto Agronômico dó Estado de São Paulo e, em laboratório, tratado pelo clássico método do funil de BAERMANN para pesquisa de Nematóides.

O "Matricidal endothokie" foi descrito pela primeira vez por SEURAT em sua "Histoire naturelle des nématodes de la Berbérie" (1920), o qual deu ao fenômeno a denominação referida.

Constatando-o em Rhabditis sp., do Brasil, julgamos interessante elaborar estas notas a respeito do assunto. 
A explicação da anormalidade é a seguinte : a fêmea de Rhabditis acha-se com ovos, prontos para serem lançados ao exterior. Contudo, ou por uma causa patológica, ou decorrente de senectude, a fêmea não consegue fazer a expulsão dos ovos e êles eclodem dentro do útero. As larvas recém nascidas, necessitando nutrir-se, põem-se a comer os tecidos do corpo da mãe, chegando a devorá-los integralmente. $\mathrm{E}$ o resultado é o encontro de fêmeas como as que desenhamos com o auxílio da câmara clara (Figs. 1 e 2), após fixação pelo formol a 6\%.

A fig. 1 mostra uma fêmea com três larvas robustas em seu interior. Pràticamente, todo o conteudo foi ingerido por elas. Apenas restam a cavidade bucal e o esôfago e configurações, por certo correspondentes a produtos de eliminação das próprias larvas.

As dimensões encontradas para os indivíduos forain, em microns, as seguintes, tendo sido as larguras tomadas ao nível do meio do corpo:

Fêmea :

Larvas :
$792 \times 52$.

$290 \times 22$.

$220 \times 20$.

$220 \times 17,6$.

$\mathrm{Na}$ fig. 2, o corpo da fêmea acha-se também pràticamente vazio, tomado integralmente pelas quatro larvas. $O$ pouco que resta do tubo digestivo está em adiantado gráu de desorganização, em virtude da ação mecânica desenvolvida pelas larvas.

As dimesões tomadas foram:

Fêmea :

Larvas : $\cdot 763 \times 44$.

$198 \times 15,40$.

$233 \times 15,40$.

$220 \times 13,20$.

$220 \times 13,20$.

Os dois casos dizem que a porção inicial do tubo digestivo (cavidade bucal e esôfago) é aproveitada pelas larvas em último lugar, pois examinamos casos em que nada aparecia.

As dimensões atingidas pelas larvas está, evidentemente, na dependência de seu maior ou menor número por fêmea. Na espécie em estudo, foi de 6 o número máximo verificado. 

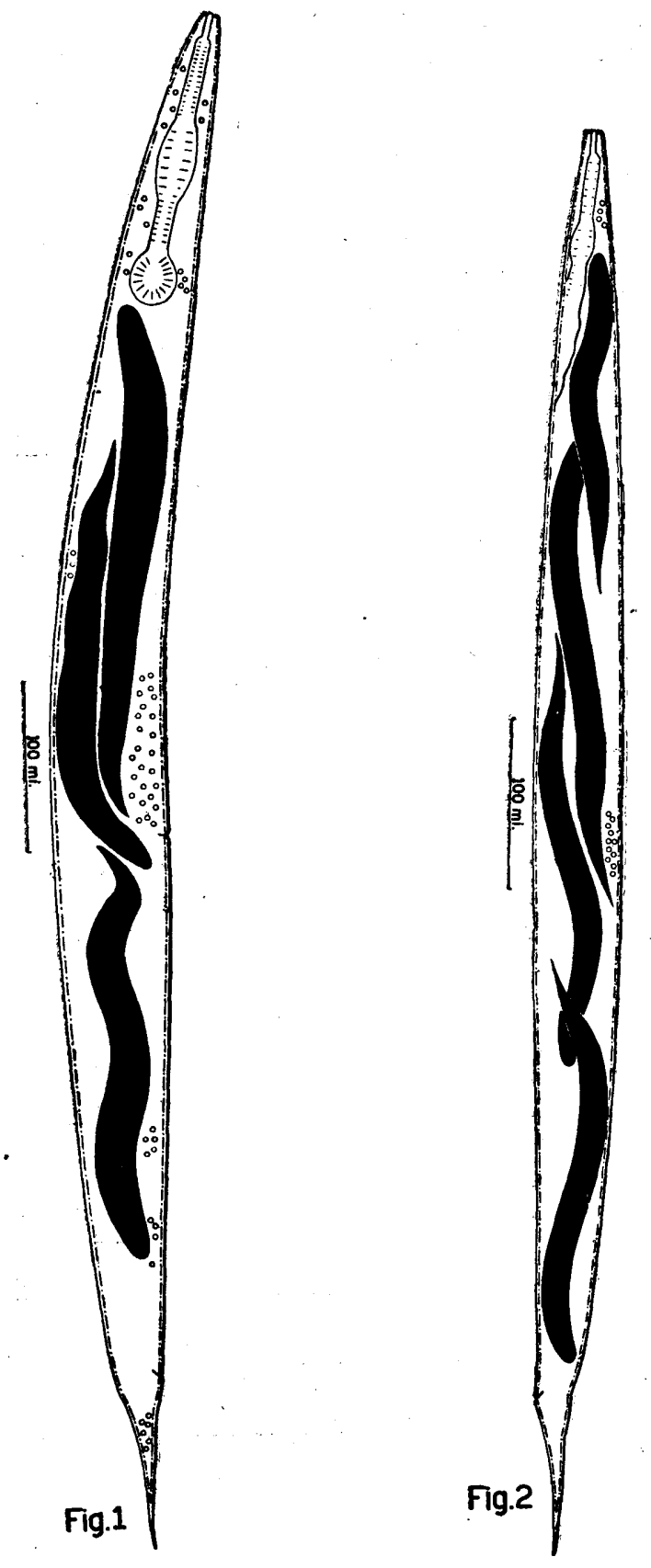
Prêsas no interior da mãe, as larvas movem-se continuamente, em tentativas para ganhar o exterior. Os seus movimnentos, transmitindo-se para as paredes do corpo da fêmea, nos dão a impressão, quando observados com pequeno aumento, de estarmos diante de um Nematóide vivo, sem qualquer anormalidade. No ponto em que a larva faz a volta para caminhar para trás, forma-se um abaulamento no corpo da fêmea, dada a elasticidade da cutícula.

As larvas, ao que se sabe, nem sempre conseguem romper a cutícula e ganhar o exterior, tal a resistência que ela oferece, Acabam perecendo. Aliás, são bem conhecidas as propriedades da cutícula de Rhabditis, inclusive quanto a sua impenetrabilidade por agentes químicos. A êste propósito, o fato seguinte nos parece interessante: fêmeas de Rhabditis, carregadas de ovos, foram fixadas pelo Flemming forte. Algum tempo após, observadas ao microscópio, mostravam larvas vivas em seu interior; os ovos nada haviam sofrido como o tratamento e tiveram eclosão normal. (Comunicação do Dr. G. Steiner, Diretor da Division of Nematology do U. S. Department of Agriculture).

A espécie de Rhabditis a que nos referimos nestas notas, muito abundante no material examinado, é Anfidélfica, isto é, apresenta dois ovários, um anterior e outro posterior em relação à vulva.

Não encontramos nenhum macho. Todos os exemplarts examinados eram fêmeas, podendo mesmo tratar-se de uma espécie monosexual.

\section{SUMMARY}

The phenomenon called "Matricidal endothokie" was, by the first time, described by SEURAT in his "Histoire naturelle des némattodes de la Berbérie".

In this paper, the Author describes two cases of the same phenomenon in Rhabditis sp. collected from soil around carrot roots from the Estação Experimental de Monte Alegre do Sul,belonging to the Instituto Agronômico (State of S. Paulo, Brasil).

In addition to the description, the Author makes some considerations about this interesting phenomenon, as well as, about the studied species, in which it occurs very frequenteiy. 